\title{
The Investigation of P1 gene in Mycoplasma pneumonia Isolated from atypic pneumonia by molecular methods, determine IgG antibody and MIC to ciprofloxacin antibiotic
}

\section{Zohre Darabi}

Shahed University Faculty of Medical Sciences

Mohammad Niakan ( $\nabla$ niakan@shahed.ac.ir)

Shahed University Faculty of Medical Sciences

Mansoor Khaledi

Shahed University Faculty of Medical Sciences

Hamed Afkhami

Shahed University Faculty of Medical Sciences

\section{Saeid Javdan}

Isfahan University of Medical Sciences

\section{Zahra Darabi}

Islamic Azad University of Tehran: Islamic Azad University Central Tehran Branch

\section{Research}

Keywords: Mycoplasma pneumonia, Atypicalpneumonia, Ciprofloxacin, Drug resistance

Posted Date: January 18th, 2021

DOl: https://doi.org/10.21203/rs.3.rs-145863/v1

License: (c) (i) This work is licensed under a Creative Commons Attribution 4.0 International License. Read Full License

Version of Record: A version of this preprint was published at New Microbes and New Infections on January 1st, 2022. See the published version at https://doi.org/10.1016/j.nmni.2022.100954. 


\section{Abstract \\ Objective}

Mycoplasma pneumoniae, which causes atypical pneumonia, is a well-established pathogen of the respiratory tract. This bacteria is intrinsically susceptible to fluoroquinolones. But Recently, drug-resistant forms of this bacteria have been reported. This study aims to determine the prevalence of this bacteria by ELISA and PCR and MIC to ciprofloxacin.

\section{Methods}

The clinical samples (blood and nasopharyngeal swab) were collected from 100 patients who were referred to selective hospitals in Tehran with respiratory complaints were enrolled in 2017. Nasopharyngeal swab sample collections were cultured on PPLO broth and PPLO agar. After culturing and DNA extraction, PCR was performed by specific P1 genes primers. Ciprofloxacin's MIC of Mycoplasma pneumonia isolated was determined by Micro-broth dilution method. Also, measure serum IgG antibody titers were measured by ELISA Mycoplasma pneumonia.

\section{Results}

In this study, out of 100 samples 12, bacteria were isolated on PPLO agar.Using specific primers,7 samples of Mycoplasma speciesism-specific were positive for the presence of M.pneumoniae. 2 Ciprofloxacin resistant isolates were evaluated. ELISA results show that the $\lg \mathrm{G}$ titre antibody In 19 samples is existent. Also, 5 samples are intermediate. IgG antibody titre average in the whole sample is $27 / 66 \mathrm{U} / \mathrm{ml}$ but it is in Positive samples by P1 PCR is $45 / 75 \mathrm{U} / \mathrm{ml}$.

\section{Conclusions}

This study showed that PCR is a sensitive and reliable method for rapid detection of M. pneumoniae bacteria in respiratory infectious samples.but the results of this method are different from the ELISA method. also, It seems that the Resistance to ciprofloxacin is relatively common among M. pneumoniae.

\section{Introduction}

M. pneumoniae is one of the main etiological agents causing atypical pneumonia, especially in children and young adult [ $[1-3]$.It accounts for as many as $10-30 \%$ of all cases of community-acquired pneumonia (CAP) $[2,4]$.Epidemiological studies in China have demonstrated that $M$. pneumoniae infections account for $20.7 \%$ in adult cases, more than Streptococcus pneumoniae, and turn out to be the leading pathogen of CAP[2]. Although most of these infections are mild and often self-limiting, severe bronchopneumonia and lung abscesses can occur. Furthermore, M. pneumoniae infections may also lead 
to several extra-pulmonary conditions, such as myocarditis, pericarditis, meningitis, neuritis, and hemolytic anemia, sometimes with fatal outcomes [5-7].

Because treatment of $M$. pneumoniae infections with $\beta$-lactam antibiotics is ineffective and the clinical manifestations of $M$. pneumoniae infections are complicated and nonspecific, a rapid, sensitive, and specific laboratory test is vital for early diagnosis of $M$. pneumoniae infection $[8,9]$.Conventional tests, including cultivation and serological methods, have their limitations in detecting M. pneumoniae. For example, M. pneumoniae culture is difficult, time consuming, and lacks sensitivity, and is therefore not recommended for clinical practice $[4,10]$.Serological methods are currently the most common tool used in the clinical laboratory. However, these methods have practical limitations because of the availability of paired serum samples from both acute and convalescent phases, and provide results of questionable specificity and sensitivity[10-12] .

Both the $P 1$ adhesin gene and $16 S$ rRNA gene have been utilized widely in PCR techniques as the targets for detection of M. pneumonia [13-15]. The $P 1$ adhesin gene is an intriguing target gene for PCR because of its repetitive nature within the genome[14]. About $8 \%$ of the $M$. pneumoniae genome consists of repetitive DNA elements with regions homologous to the $P 1$ adhesin gene, thus allowing an increase in the sensitivity of a PCR assay [16].

Several bacterial surface proteins, including $170-\mathrm{kDa}$ protein, $P 1$, are involved in the formation of the attachment organelle and cytadherence of $M$. pneumoniae to the respiratory epithelium. The 170-kDa protein $P 1$ is a majora adhesin protein which is densely clustered at the site of the attachment organelle[17] .Protein $P 1$ is encoded by a gene of nearly 5,000 bp, comprising copies of repetitive regions RepMP2/3 and RepMP4, which are present in the M. pneumoniae genome in 10 and 8 copies, respectively[18] .

The 16S rRNA gene is also an attractive candidate as a target due to its unique organization and the presence of conserved and variable regions on its abundant high-copy number[14, 19].As for which of them is the better choice, there is still no uniform standard.

Since mycoplasmas lack a cell wall, the number of antibiotics that can be used for treating mycoplasmal infections is limited. Antibiotics with potential activity against mycoplasmas and used in clinical practice include the tetracyclines, MLSK antibiotics and fluoroquinolones[20, 21]. These drugs achieve high intracellular concentrations in mammalian cells and are thereby able to reach the intracellular mycoplasmas. Only the fluoroquinolones and ketolides have a potential bactericidal action. All three classes have the advantage of being active against other bacteria that may be associated with mycoplasmas in respiratory and genital tract infection.

The first members of the fluoroquinolone class, such as ofloxacin and ciprofloxacin were followed by new agents, like levofloxacin and moxifloxacin. Newer fluoroquinolones show an enhanced activity against all the human mycoplasmas studied including M. pneumoniae, compared with the older ones. However MICs of all fluoroquinolones are higher than those of macrolides and related antibiotics [22]. 
The aim of this study was to measure the presence of this bacteria by molecular and ELISA methods, evaluate the presence of $P 1$ genes in isolates, also, IgG antibody titer against this bacteria was also measured by ELISA method and Finally, the minimum inhibitory concentration(MIC) is determined by the antibiotic ciprofloxacin (as common fluoroquinolones.

\section{Materials And Methods}

\section{Strain collection and sampling}

In this study, 100 people with pneumonia were hospitalized and samples were taken in selected hospitals in Tehran. The disease was confirmed by a physician based on criteria such as clinical symptoms, chest radiography, and patient history. Sampling was performed in June-February 2017.

Using a sterile disposable syringe (Yazd syringe), blood samples were taken from all individuals and poured into the test tube containing clot activator. The sterile swab (Dacron ${ }^{\circledR}$ swab) in the test tube containing the transfer medium was used to sample the pharynx. The transmission medium used is PPLO broth (BBL medium - China). Throat swabs were prepared from patients. The swabs were transferred to the laboratory for culture after numbering in the vicinity of ice (4 degrees Celsius( .

\section{Selection of specific mycoplasma pneumoniae culture medium and culture of isolated samples}

PPLO agar and PPLO Broth (BBL medium - China) were used to cultivate the samples. The selection of these two culture media was based on the availability of manufacturing facilities and the availability of a growing medium. To prevent the growth of bacteria in the sample, penicillin, amphotericin $B$ and polymyxin solutions should be added to PPLO Broth culture medium. The solution for these solutions should be prepared before the start of the production process, also, D-Glucose solution must also be added to the culture medium for bacterial growth.

Isolated isolates must be cultured after the M. pneumoniae culture medium has been cultured and the necessary ingredients have been added. Cultivation of $M$. pneumoniae For this purpose, in sterile conditions, using a syringe, one milliliter of the culture medium was removed and transferred to PPLO Broth solution by 0.45 micron filter of the syringe head with low pressure. The culture medium was monitored at 37 degrees Celsius and incubator for 21 days. During this time, color changes (color of the reagent) or turbidity were monitored. After 21 days, $1 \mathrm{ml}$ of each medium was added to the secondary culture medium (the third regrowth from the time of sampling). PPLO agar plate was added from all 0.5 $\mathrm{ml}$ culture media. The plates were transferred to a 37 degrees Celsius incubator. The incubator contained a $\mathrm{CO} 2$ atmosphere (5-10\% concentration). The plates were evaluated daily for 3-7 days. Bacterial growth status was evaluated using 10X optical microscopy with magnification was re-cultured from the transition medium.

\section{PCR molecular test}

\section{Bacterial preparation:}


PPLO Broth was poured $0.5 \mathrm{ml}$ of culture medium (re-culture medium) into the $1.5 \mathrm{ml}$ microtype. This was done using a sterile sampler. The microtubules were centrifuged at 13,000 rpm for 15 minutes (Sigma-Germany). The supernatant was removed and bacterial sediment was used to extract the DNA. In order to positively control the DNA extracted from the bacterium M. pneumoniae (29342: ATCC-produced by Razi Institute) and for negative control, a culture medium without bacteria was used.

\section{DNA Extraction}

Genomic DNA for subsequent PCR was done using the Roche kit and taking into account the kit instructions.

\section{Preparation primer}

The sequence of primers for the $P 1,16 S r R N A$ genes specific for the $M$. pneumoniae species used in previous studies was evaluated. This assessment was performed using Oligo Primer Analysis Software version 7. After the approval of the desired primers, the order to make the primers was sent to Sina Cloon. The sequence of primers used in this study is presented in Table 4. It should be noted that the PCR reaction is performed to confirm the molecular identity of the isolates using the P1 Mycoplasma pneumoniae-specific primer, while the reaction was performed to determine the bacterial abundance in the swab using a 16SrRNA-specific Mycoplasma primer.

\section{PCR process}

Molecular detection of $P 1,16 S r R N A$ and was carried out according to the following condition:

initial denaturation at $72{ }^{\circ} \mathrm{C}$ for 5 min followed by 35 cycles of denaturation at $72{ }^{\circ} \mathrm{C}$ for $45 \mathrm{~s}$, annealing at $63{ }^{\circ} \mathrm{C}$ for $40 \mathrm{~s}$, and extension at $95^{\circ} \mathrm{C}$ for $45 \mathrm{~s}$, and final extension step at $95^{\circ} \mathrm{C}$ for $5 \mathrm{~min}$.

The sequences of all used primers are shown in (all reactions performed in duplicate and along with the negative control (water) and positive (previously known positive-PCR products) control. The positive DNA control bacterium M. pneumoniae, produced by the Razi Institute, was also used for its qualitative control. The final products were detected by electrophoresis on $1 \%$ agarose gel containing DNA safe stain (Sinacolon, Iran). The marker used in the SMO BIO survey was made by Cena Cloon with a distance of 100 pairs of open weights from 100 to 3000 pairs.

\section{MIC test}

\section{After preparing a special culture medium for this test, the bacteria are prepared.}

Dilution microbial method requires a bacterial solution with a certain concentration. If the concentration of the bacterium is not known, the amount of inhibition of bacterial growth will not be accurate. In order to determine the MIC inside the test tube, a very high concentration (comparing the turbidity with the McFarland scale) is used. However, such a concentration is not possible for the bacterium M. pneumonia. 
For this purpose, a suspension containing $10^{4}-10^{5} \mathrm{CFU}$ is used. This suspension is prepared using the colon count method on PPLO Agar environment. Bacteria that were positive for $P 1$ genes were cultured and the number of CFUs in the reference suspension was calculated using a reverse microscope. The CFU in bacterial suspension was then adjusted accordingly.

After the preparation of the bacteria, the antibiotic solution ciprofloxacin was prepared. According to the CSLI 2010 table, the antibiotic potency of ciprofloxacin was 50\%. The amount of antibiotic powder required to prepare $1 \mathrm{ml}$ of ciprofloxacin solution was calculated according to the CSLI table.

For this purpose, 2048 micrograms of ciprofloxacin powder was dissolved in $1 \mathrm{ml}$ of $98 \%$ ethanol (it is difficult to measure weight on a microgram scale, so a concentrated solution was prepared and then volume was added). Dilution of the solution was performed using pure water.

\section{A 96-well plate well was used for bacterial culture for MIC test.}

In order to investigate each sample (bacterial culture), 19 wells were considered. For this purpose, the first well was considered as a positive control containing $150 \mu$ of PPLO broth medium and $150 \mu \mathrm{l}$ of bacterial suspension. (Growth in this well indicates that the bacterium is active.)

The second well is diluted at 270 microliters from the PPLO broth culture medium and 30 microliters from the antibiotic suspension. Subsequent wells up to the 18th well contain 150 microliters of PPLO broth. From the second well, $150 \mu \mathrm{l}$ of solution was transferred to the third well after complete pipetting. The transfer of the solution from the previous well to well 18 continued. 150 microliters will be discarded from the 18 well solution. $150 \mu \mathrm{l}$ of the bacterial suspension was added to wells $2-18$ and each half $0.5 \mu \mathrm{l}$ of bacterial suspension. $300 \mu \mathrm{l}$ of PPLO broth culture medium was added to well 19 . Well 19 plays the role of Blanc.

\section{Determination of specific IgG antibody titer of Mycoplasma pneumonia:}

For this purpose, the serum was first separated from the patients' blood using centrifugation and kept at -20 Celsius until further steps.

In this study, Kate-EUROIMMUN (made in Germany) was used to perform the ELISA test.

The test was performed using a quantitative method (due to greater accuracy). This method is used to measure the antibody level of $M$. pneumoniae. The test was performed using the instructions in the kit, and finally the standard kit curve was used to calculate the curve results (reading results). Accordingly, values less than 16 units per milliliter were considered as a negative result, and between 16 and 22 as an intermediate result. Values greater than 22 units per milliliter were also considered positive results. The results were read using Eliza Reader (Biotech-USA).

\section{Statistical analysis}


In this study, information was evaluated using SPSS software (IBM-USA-version 12). For this purpose, Spearman, Anova, Chi-square and T-tests (to compare the results of the two methods) were used. A significant criterion for statistical differences was $P$ values smaller than 0.05 .

\section{Results}

\section{Culture result}

Among the cultured samples, 12 bacterial isolates with egg and strawberry morphology were obtained. The structure of the half-egg on the PPLO culture medium is shown in Fig 1.

\section{PCR results for the 16srRNA and the P1 gene}

In order to determine the contamination of the specimens, bacteria of the genus Mycoplasma PCR were performed. DNA was extracted from all samples. A special 16srRNA primer made of mycoplasma was used. The piece is about 713bp long (based on the primer structure). Accordingly, 14 samples infected with Mycoplasma bacteria were considered. The PCR image of a piece of the 16srRNA gene of the Mycoplasma pneumonia is shown in Fig 2.

PCR of the $P 1$ gene was performed to confirm the molecular identity of the clones obtained. Due to the specificity of the primer at the cheek surface, PCR results testify to the presence of mycoplasma pneumonia. After DNA extraction and proliferation of the $P 1$ gene, it was proved that all isolated bacteria are $M$. pneumonia. Based on the results obtained from PCR, the identity of $M$. pneumonia was confirmed in 7 isolates. Fig 3 shows an example of the results of $450 \mathrm{bp}$ proliferation of the P1 gene of $M$. pneumonia.

\section{Results of the population indicators of people infected with M. pneumonia}

In this study, various population indicators of people infected with M. pneumonia were studied. These indicators included smoking, coughing, sinusitis and asthma, and muscle aches.

1. In connection with the smoking, Using a square statistical test, the overall difference between tobacco use and non-smoking in infection caused by pneumococcal mycoplasma was determined. $p$-value $=0.671$ obtained indicates that there is no significant statistical difference between the consumer group of tobacco and the group without consumption.

2. Based on the type of cough, the participants in this study were divided into four subgroups (dry cough, whooping cough, no cough, whooping cough and whooping cough). The statistical relationship between cough and infection with M. pneumoniae is presented in Table 1. Therefore, in this study, the occurrence of dry cough, which is one of the symptoms of $M$. pneumoniae, has no statistical relationship of infection with this bacterium.

3. Among people infected with M. pneumoniae, $2(28 \%)$ people with sinusitis were evaluated and among those without infection, 10 (10.7\%) people with sinusitis were evaluated. In terms of 
statistical test, these values do not differ ( $p$-value $=0.62)$.

4. Among the participants in this study, 5 people with asthma were evaluated. None of the people infected with M. pneumoniae had asthma.

5. Muscle pain is one of the extrapulmonary symptoms of $M$. pneumonia. However, this symptom is not specific to the M. pneumoniae, and other pneumonia-producing organisms indicate this symptom. In this study, out of 100 patients evaluated, 27 reported muscle pain complaints, of which 4 were infected with pneumococcal mycoplasma and 23 were non-infectious. Kai's square statistical test showed that there was no association between muscle pain and infection with mycoplasma pneumoniae $(p-v a l u e=0.06)$. However, this result is significantly closer.

\section{Mic result}

11 M. pneumoniae isolates were evaluated using microdermabrasion method for microbial resistance to ciprofloxacin. Of the 7 mycoplasma pneumoniae isolates, 2 (28\%) isolates were evaluated as resistant to ciprofloxacin. Table 2 and Fig 4 presents the results of this test.

\section{ELISA result}

Based on the results of the ELISA test, the specific IgG antibody titer of $M$. pneumoniae was evaluated positively among 19 of the 100 participants in this study. There were also 5 intermediaries. The lowest serum level among these individuals was 1 unit and the highest titration rate was 98. Fig 5 shows the frequency distribution of IgG antibodies in the subjects in this study.

Fig 6 also shows the frequency distribution of different IgG antibodies to pneumococcal antimicrobial $\lg G$.

\section{.Comparison of antibody titers and PCR}

7 cases were evaluated for culture and PCR infection infected with M. pneumoniae. Antibody titer in these individuals is presented in Table 3. The table also includes the headlines of people who were positive for Mycoplasma infection.

\section{Discussion}

M.pneumoniae is a bacterial pathogen without a cell wall of the respiratory tract that infects the respiratory tract. The bacterium is also one of the leading causes of acquired pneumonia in the community. The most common manifestations of m.pneumonia include flu-like symptoms such as sore throat, fever, cough, headache, chills, colds, muscle aches, and general discomfort. M.pneumoniae infection occurs worldwide and is most common in children and adolescents. M.pneumoniae is transmitted primarily from close contact with another person. In recent years, pneumonia caused by mycoplasma has increased. Pneumonia caused by M.pneumoniae occurs through damage to the airways of the lungs in a contagious manner and inflammation caused by M.pneumoniae. 
The pneumonia caused by this bacteria is generally resistant to treatment with beta-lactam antibiotics. It depends on the structure of the bacterium because it is unable to produce peptidoglycan. However, allergies to other antimicrobial agents are seen in this bacterium. However, resistance to antibiotics in this bacterium has been discussed in many societies. If left untreated, some patients may develop the disease [23].

Data from more than 21 countries showed that m.pneumoniae is the most common type of bacterium that causes atypical pneumonia, which is responsible for creating about $12 \%$ of the acquired pneumonia in the community. Past studies on m.pneumoniae have shown that they are $40 \%$ more likely to develop acquired pneumonia.. A recent cross-sectional study of people with atopic pneumonia showed generally lower data rates than in any other country. Climate differences, seasons, and improved environmental and public health are likely to reduce the risk of contracting the bacterium. In general, because it is difficult to diagnose mycoplasma biochemistry, little research is available on other bacteria. The slow growth and susceptibility of the bacterium can also double the accuracy and sensitivity of the techniques used to diagnose it.

The main strategy of this study, according to its title, was first to answer the question of what is the prevalence of m.pneumoniae in people with atopic pneumonia. The next step was to measure the drug's resistance to ciprofloxacin in the resulting isolates. The first goal (frequency determination) was performed in three different ways. Cultivation method, PCR molecular method and ELISA method.

In the present study, we joined orthogonal experiment and single-factor tests to optimize several crucial factors in PCR assay based on both the 16S rRNA gene and $P 1$ adhesin gene designed for $M$. pneumoniae detection.

Gene targets used widely in various types of PCR assays for $M$. pneumoniae include the $P 1$ adhesin gene and $16 S$ rRNA gene[13]. The $P 1$ adhesin gene is an attractive target for PCR because it repeats up to 10 times within the M. pneumoniae genome, which increases the sensitivity of PCR assay[16]. Another important target is $16 S$ rRNA, or rather rDNA. The advantage of using rDNA sequences is the high degree of conservation of the target and the presence of the highly variable regions[14].Therefore, it would be greatly valuable for guiding treatment decisions and follow-ups, particularly in countries with a high frequency of strains resistant to antibiotics, because the confirmation of $16 S$ rDNA could be applied in discriminating between bacterial and viral causes of pneumonia.

To our knowledge, however, it is still controversial which target is more effective. For instance, Loens et al. suggested that the $P 1$ adhesin gene may be more sensitive than the 16S rRNA one[13]. Two independent researchers, nevertheless, showed that the amplification of the 16S rRNA gene was more sensitive for the detection of M. pneumoniae because more positive samples were found by $16 S$ rDNA PCR than by a PCR with the $P 1$ gene[14, 15]. The main reason for the ambivalent conclusions is that the researchers detected the DNA directly from clinical samples, rather than a standard strain DNA of $M$. pneumonia, to compare the sensitivity of $16 S$ rDNA PCR with P1 gene PCR. 
These results confirmed that the $16 S$ rRNA gene primers are more sensitive than the $P 1$ adhesin gene primers, as the $16 S$ rRNA gene primers can detect up to $10 \mathrm{fg}$ of $M$. pneumoniae DNA and the $P 1$ gene primers can detect $100 \mathrm{fg}$ of M. pneumoniae DNA at most. This was mainly because the presence of approximately 103 copies of $16 S$ rRNA per mycoplasma cell and the high degree of conservation of the rRNA genes allowed a high fixation of primers on the target and lead to a higher PCR yield[4, 14] .Importantly, because RNA is destroyed more rapidly than DNA after the death of the mycoplasma cell, detection of the 16S rRNA gene provides further evidence of viable mycoplasmas in the specimen [4].

At this stage, part of the $16 S r R N A$ gene of this bacteria was replicated. Propagation was performed using mycoplasma-specific primers. The second step was to use the PCR technique using specific $P 1$ gene primers.

Primer $\mathrm{F}$ has a general structure, but primer $\mathrm{R}$ (return) has a specific structure for screening for mycoplasma. In 2014, Tabatabai Qomi et al. Used these primers to examine the presence of mycoplasma as a contaminant in cellular categories. In addition to M.pneumoniae, they identified other bacteria of this genus. Bacteria including Mycoplasma arginini, Mycoplasma hyorinis, Mycoplasma orale, Mycoplasma synoviae, Mycoplasma gallinarum were also identified[24] .

We observed that $0.14 \%(14 / 100)$ of the specimens were positive with the 16 S rRNA gene PCR and $7 \%$ $(7 / 100)$ of the specimens were positive with the $P 1$ adhesin gene PCR.

The first use of these primers dates back to 1995 and research by Pruckler et al. The aim of this study was to study the species of M.pneumoniae that can be traced in cellular categories [25].

In 2014, Mirihan et al. Used this primer to study the infection with Mycoplasma bacteria in patients with pneumonia admitted to Egyptian hospitals. They assessed a prevalence rate of $22.94 \%$ among 170 individuals. In the present study, a prevalence of $14 \%$ was observed, which is lower than that of Mirihan et al. The reason for this decrease is probably related to Iran's health conditions [26].

Determination of M.pneumonea species was also determined by specific proliferation of $P 1$ gene. The results of this study showed that 7 samples are infected with M.pneumoniae. Another 7 samples were positively evaluated for mycoplasma. The identity of the infected species remained unknown.

In 2015, Amirian et al. In Saveh city used PCR method to diagnose M.pneumoniae using $P 1$ gene proliferation. Out of 120 people with chronic lung infection, 8 were positive, with the highest frequency in the 21-year-old age group and the lowest in the 3-year-old age group [27].

The positive PCR result is based on the 16SrRNA gene, but the lack of bacterial growth is due to the origin of the microbial agent. The bacteria is present and is made of mycoplasma but is unable to grow. Yoshida et al., Using similar primers and replicating part of $16 \operatorname{SrRNA}$, isolated the specific species of birds related to the genus Mycoplasma [28]. 
Cultivation is rarely used for diagnosis of $M$. pneumoniae infection in most clinical laboratories because the fastidious growth requirements and length of time necessary to culture M. pneumoniae (three to six weeks) make growing the organism impractical for patient management $[4,10]$.

Currently, serological assay is the most widely used means for laboratory confirmation of mycoplasmal respiratory infections [10]. However, there are concerns about the use of single qualitative tests to identify acute $M$. pneumoniae infections in adults, since many persons may not mount an IgM response, presumably because of re-infection, and when it is produced, IgM may persist for long periods $[19,29,30]$. Furthermore, the percentage of individuals with acute infection who demonstrated a positive IgG response in the acute phase was less than $50 \%$ in a recent study.

It has been suggested that cross-reactivity with antigen preparations used in some of the commercial enzyme immunoassays (EIAs) result in over-diagnosis of M.pneumoniae infections[29]. Therefore, even if serology is a useful epidemiologic tool in areas where the infection rate of M. pneumoniae is high, it is less suited for assessment of individual patients in clinical laboratories[11]. Compared with serology and culture, a direct detection of pathogens in clinical specimens has been done more regularly using molecular biology techniques. PCR approaches have been the most valuable method for rapid, sensitive, and specific diagnosis of $M$. pneumoniae infection[4]. However, the application of molecular methods of enhanced sensitivity may be necessary since the pathogens are probably present in small quantities.

In 2003, Orsi et al. Evaluated the performance of four PCR-based M.pneumoniae identification methods. In this study, false PCR results were confirmed. This study proves that bacterial culture is the most reliable way to measure mycoplasma in terms of false positives. However, based on this study, the false negative results of the cultivation technique are high[13].

In 2006, Shah Hosseini et al., Using culture and PCR methods, compared the performance of these two methods to identify pneumococcal mycoplasma in people with acquired pneumonia. According to their research, all cases of positive culture in terms of PCR will also be positive. Therefore, PCR was considered an accurate and hypersensitive method of culture [31].

In 2013, in a study using serology and PCR, Noorbakhsh etal.Studied the role of m.pneumoniae in children with adenoid hypertrophy and rhinosinusitis. Positive PCR results were reported in $35 \%$ of the samples. A survey of antibody titers by ELISA also found that 10 percent of people with IgM and 20 percent had IgG in their serum. In this mycoplasma, pneumonia was also detected using PCR in adenoid tissue samples[32] .

In the present study, data from the ELISA method showed that out of a population of 100 people studied, 19 contained specific anticoagulants of M.pneumoniae. This rate is negligible compared to many other studies. In 2002, for example, Rastawick et al. Found that $63 \%$ of the 66 patients admitted to Polish hospitals had specific IgG antibodies specific to m.pneumoniae [23]. This high level is probably dependent on factors such as the antibody titer determination kit. 
In addition, reviewing the ELISA results and comparing it to the PCR test reveals a valuable point. All seven samples infected with M.pneumoniae were also positive for ELISA. This shows the importance of positive ELISA results. However, species of the genus Mycoplasma (other than Mycoplasma pneumoniae) were unable to increase its antibody titer.

in 2001, Suni et al. Used the ELISA method to investigate the prevalence of Mycoplasma pneumoniae infection in people with acute and non-acute pneumonia. They showed that 92 out of 210 people tested positive for IgG mycoplasma pneumoniae in their serum [33].

Sharifi et al. In 2011 in Tabriz, using PCR, culture and ELISA methods, examined the frequency of respiratory infections caused by M.pneumoniae. In addition, they measured patients' IgM antibody titers. Out of 200 patients with pneumonia, 12 samples were evaluated by PCR method infected with this bacterium. Also, 4 samples were isolated by m.pneumoniae bacterial culture method. Using ELISA technique, it has been proven that there are 10 mycoplasmal $\operatorname{lgM}$ antibodies in the serum of individuals [34].

In 2004, in Tehran and in Tehran, Niakan et al. Used the ELISA method to investigate the serological frequency of IgG associated with m.pneumoniae in people with atypical pneumonia. ELISA method was used in their research. Blood serum was assessed in 104 individuals, of which $57 \%$ were positive. $36 \%$ were negative and $5 \%$ were intermediate [35].

In this study, samples tested positive for M.pneumoniae were evaluated for MIC in terms of ciprofloxacin. The result of this evaluation was resistance 2 separation. Restriction of m.pneumoniae in treatment (intrinsic resistance to beta-lactam antibiotics) has led to the treatment of this bacterium as a sensitive issue. There is an increase. For example, 80 to 90 percent prevalence of macrolide resistance leads to ineffectiveness as one of the most important and effective factors in their treatment [36].

On the other hand, research on m.pneumoniae and its antimicrobial properties is much more difficult than other bacteria. Therefore, the main focus is on the limited scientific reports provided from various sources. This has led to the fact that these reports, like the report from the present study, are of particular importance. The prevalence of 2 resistant isolates among the 8 resistant isolates (in the present study) compared to the prevalence reported in the Gruson study, and colleagues reported the resistance of this bacterium against resistant strains. It had the highest resistance among all antibiotics. The maximum reported MIC for ciprofloxacin in the Gruson study was 128 micrograms per milliliter. And the minimum MIC value was 1 microgram per milliliter. The fact that the bacterium Mycoplasma pneumoniae is more resistant to ciprofloxacin than other antibiotics is a warning sign of an increase in its prevalence. However, in our country, this increase in resistance is not seen. To confirm this, we can refer to the research of Kashmiri et al. In 2014. In general, the prevalence of resistance is 2 isolates less than 7 isolates than the $81 \%$ resistance of macrolides in Japan [37] and less than $7.5 \%$ of the resistance of levofloxacin in Europe (France) [38]. 
In 2011, Aizhen et al. Investigated the therapeutic response to concomitant use of ciprofloxacin and corticosteroids in the treatment of infections caused by m.pneumoniae. They found combination therapy to be effective. However, some people experience delayed fever and symptoms that appear to be genetically predisposed. This study shows that the patient's genetics are involved in the symptoms and treatment of pneumococcal mycoplasma [39].

In 2014, Biljana et al. Examined the role of community-acquired pneumonia created by M.pneumoniae. 166 children aged 1 to 15 years were assessed. In this study, serological methods and RT PCR technique were used. Specific IgM and IgG antibodies to m.pneumoniae were measured in patients' serum. During this study, the clinical symptoms of M.pneumoniae, including headache, wheezing, were evaluated. It was also found that $14.5 \%$ of people with m.pneumonia [40].

\section{Conclusion}

M.pneumoniae is one of the smallest release and pathogenic organisms. This bacterium has problems in diagnosis and treatment. The inability to perform biochemical tests on it doubles the need for epidemiological studies. The next important thing about this bacterium is its treatment. There have been recent reports of widespread resistance to M.pneumoniae. Antibiotic-based treatment has led to widespread concern about the spread of this resistance among the scientific community. In the present study, the diagnosis of pneumococcal mycoplasma was made using $P 1$ gene culture and PCR method. Although the results of this experiment were lower than the ELISA results, the ELISA did not have a false positive. In this study, 14 isolates based on PCR gene of 16SrRNA gene were identified as a part of mycoplasma species. PCR was then used to identify the $P 1$ gene, which resulted in the identification of seven species. Thus, 7 other species were evaluated as non-Mycoplasma pneumoniae species. A survey of the questionnaire showed that 9 out of 14 people are related to birds. The presence of domestic birds and contamination with the M.pneumoniae are also statistically related. Ciprofloxacin MIC testing showed that the 2-isolate bacterium is resistant, which is not very significant compared to other antibiotic reports.

\section{Declarations}

\section{Acknowledgements}

This manuscript is part of a MSc thesis. This study is financially supported by Shahed University of Medical Sciences in 2017-2018. The authors of current study would like to express their deep thanks to all laboratory staff of Shahed University of Medical Sciences.

\section{Author contributions}

ZD, MN, MK: design of study. ZS, MK, HA, SJ: acquisition of data. ZD, MN, ZD, SJ: evaluation of data, preparation of the manuscript. ZD, MN, MK, HA : assessment of data. All authors read and approved the final manuscript. 


\section{Funding}

This manuscript is part of a MSc thesis. This research was supported by the budget of research projects of the Shahed University of medical sciences. Funding were used to purchase equipment and tools.

\section{Availability of data and materials}

All relevant data are included in the manuscript.

\section{Ethics approval and consent to participate}

This study was in accordance with the declaration of Helsinki. This study was approved by the Ethics Committee of Shahed University of Medical Sciences. (Ethical code: IR.SHAHED.REC.1397.039). The informed consent was obtained from all the participants, and informed consent obtained was written.

\section{Consent for publication}

Not applicable.

\section{Competing interests}

The authors declare that they have no conflict of interest.

\section{Author details}

1 Department of Microbiology, Faculty of Medicine, Shahed University, Tehran, Iran

2 Department of Medical Microbiology, Faculty of Medicine, Isfahan University of Medical Sciences, Isfahan, Iran

3 Department of Genetics, Azad University, Medical Branch, Tehran, Iran

\section{References}

1. Atkinson TP, Balish MF, Waites KB: Epidemiology, clinical manifestations, pathogenesis and laboratory detection of Mycoplasma pneumoniae infections. FEMS microbiology reviews 2008, 32(6):956-973.

2. Cao B, Zhao C-J, Yin Y-D, Zhao F, Song S-F, Bai L, Zhang J-Z, Liu Y-M, Zhang Y-Y, Wang H: High prevalence of macrolide resistance in Mycoplasma pneumoniae isolates from adult and adolescent patients with respiratory tract infection in China. Clinical infectious diseases 2010, 51(2):189-194.

3. Miyashita N, Kawai Y, Yamaguchi T, Ouchi K, Oka M, Group APS: Clinical potential of diagnostic methods for the rapid diagnosis of Mycoplasma pneumoniae pneumonia in adults. European journal of clinical microbiology \& infectious diseases 2011, 30(3):439-446. 
4. Daxboeck $F$, Krause $\mathrm{R}$, Wenisch $\mathrm{C}$ : Laboratory diagnosis of Mycoplasma pneumoniae infection. Clinical microbiology and infection 2003, 9(4):263-273.

5. He X-y, Wang X-b, Zhang R, Yuan Z-j, Tan J-j, Peng B, Huang Y, Liu E-m, Fu Z, Bao L-m: Investigation of Mycoplasma pneumoniae infection in pediatric population from 12,025 cases with respiratory infection. Diagnostic microbiology and infectious disease 2013, 75(1):22-27.

6. Nilsson AC, Björkman P, Welinder-Olsson C, Widell A, Persson K: Clinical severity of Mycoplasma pneumoniae (MP) infection is associated with bacterial load in oropharyngeal secretions but not with MP genotype. BMC infectious diseases 2010, 10(1):39.

7. Youn Y-S, Lee K-Y: Mycoplasma pneumoniae pneumonia in children. Korean journal of pediatrics 2012, 55(2):42.

8. Morozumi M, Takahashi T, Ubukata K: Macrolide-resistant Mycoplasma pneumoniae: characteristics of isolates and clinical aspects of community-acquired pneumonia. Journal of Infection and Chemotherapy 2010, 16(2):78-86.

9. Zhang L, Zong Z-Y, Liu Y-B, Ye H, Lv X-J: PCR versus serology for diagnosing Mycoplasma pneumoniae infection: a systematic review \& meta-analysis. The Indian journal of medical research 2011, 134(3):270.

10. Winchell JM, Thurman KA, Mitchell SL, Thacker WL, Fields BS: Evaluation of three real-time PCR assays for detection of Mycoplasma pneumoniae in an outbreak investigation. Journal of clinical microbiology 2008, 46(9):3116-3118.

11. Nilsson AC, Björkman P, Persson K: Polymerase chain reaction is superior to serology for the diagnosis of acute Mycoplasma pneumoniae infection and reveals a high rate of persistent infection. BMC microbiology 2008, 8(1):93.

12. Thurman KA, Walter ND, Schwartz SB, Mitchell SL, Dillon MT, Baughman AL, Deutscher M, Fulton JP, Tongren JE, Hicks LA: Comparison of laboratory diagnostic procedures for detection of Mycoplasma pneumoniae in community outbreaks. Clinical infectious diseases 2009, 48(9):1244-1249.

13. Loens $\mathrm{K}$, Ursi D, Goossens $\mathrm{H}$, leven M: Molecular diagnosis of Mycoplasma pneumoniae respiratory tract infections. Journal of clinical microbiology 2003, 41(11):4915-4923.

14. Nour M, Trabelsi A, Maatouk N, Hammami M: Amplification of P1 and 16S rRNA genes by nested PCR for detection of Mycoplasma pneumoniae in paediatric patients. Pathologie Biologie 2005, 53(1):9-14.

15. Williamson J, Marmion B, Worswick D, Kok T-W, Tannock G, Herd R, Harris R: Laboratory diagnosis of Mycoplasma pneumoniae infection. 4. Antigen capture and PCR-gene amplification for detection of the Mycoplasma: problems of clinical correlation. Epidemiology \& Infection 1992, 109(3):519-537.

16. Waring AL, Halse TA, Csiza CK, Carlyn CJ, Musser KA, Limberger RJ: Development of a genomicsbased PCR assay for detection of Mycoplasma pneumoniae in a large outbreak in New York State. Journal of clinical microbiology 2001, 39(4):1385-1390.

17. Baseman J, Cole R, Krause D, Leith D: Molecular basis for cytadsorption of Mycoplasma pneumoniae. Journal of Bacteriology 1982, 151(3):1514-1522. 
18. Cousin A: Analysis of RFLPs of amplified cytadhesin P1 gene for epidemiological study of Mycoplasma pneumoniae. IOM letters, 1994 1994, 179.

19. Qu J, Gu L, Wu J, Dong J, Pu Z, Gao Y, Hu M, Zhang Y, Gao F, Cao B: Accuracy of IgM antibody testing, FQ-PCR and culture in laboratory diagnosis of acute infection by Mycoplasma pneumoniae in adults and adolescents with community-acquired pneumonia. BMC infectious diseases 2013, 13(1):172.

20. Bébéar C: Antimicrobial therapy and antimicrobial resistance. Mycoplasmas 2005.

21. Bébéar C, Pereyre S, Peuchant O: Mycoplasma pneumoniae: susceptibility and resistance to antibiotics. Future microbiology 2011, 6(4):423-431.

22. Sainath Rao S, Raghunathan M: In vitro activity of the new quinolone derivative RD-3 against clinical isolates of Mycoplasma pneumoniae and Mycoplasma hominis. Journal of antimicrobial chemotherapy 2009, 64(6):1336-1338.

23. Waites KB, Xiao L, Liu Y, Balish MF, Atkinson TP: Mycoplasma pneumoniae from the respiratory tract and beyond. Clinical microbiology reviews 2017, 30(3):747-809.

24. Tabatabaei-Qomi R, Sheykh-Hasan M, Fazaely H, Kalhor N, Ghiasi M: Development of a PCR assay to detect mycoplasma contamination in cord blood hematopoietic stem cells. Iranian journal of microbiology 2014, 6(4):281.

25. Pruckler JM, Pruckler JM, Ades EW: Detection by polymerase chain reaction of all common Mycoplasma in a cell culture facility. Pathobiology 1995, 63(1):9-11.

26. Cultrera R, Seraceni S, Germani R, Contini C: Molecular evidence of Ureaplasma urealyticum and Ureaplasma parvum colonization in preterm infants during respiratory distress syndrome. $B M C$ infectious diseases 2006, 6(1):166.

27. Michelow IC, Olsen K, Lozano J, Rollins NK, Duffy LB, Ziegler T, Kauppila J, Leinonen M, McCracken $\mathrm{GH}$ : Epidemiology and clinical characteristics of community-acquired pneumonia in hospitalized children. Pediatrics 2004, 113(4):701-707.

28. Yoshida T, Maeda S-I, Deguchi T, Ishiko H: Phylogeny-based rapid identification of mycoplasmas and ureaplasmas from urethritis patients. Journal of clinical microbiology 2002, 40(1):105-110.

29. Beersma MF, Dirven K, van Dam AP, Templeton KE, Claas EC, Goossens H: Evaluation of 12 commercial tests and the complement fixation test for Mycoplasma pneumoniae-specific immunoglobulin G (IgG) and IgM antibodies, with PCR used as the "gold standard". Journal of Clinical Microbiology 2005, 43(5):2277-2285.

30. Räty R, Rönkkö E, Kleemola M: Sample type is crucial to the diagnosis of Mycoplasma pneumoniae pneumonia by PCR. Journal of medical microbiology 2005, 54(3):287-291.

31. SHAH HMH, MARDANI M, HOSSEINI Z, KHORAM KH, RAHIMI A, VANDYOUSEFI J: COMPARISON OF PCR AND CULTURE TESTS FOR DIAGNOSIS OF MYCOPLASMA PNEUMONIAE RESPIRATORY TRACT INFECTIONS. 2006.

32. Noorbakhsh S, Farhadi M, Tabatabaei A, Darestani SG, Nia SJ: Searching Mycoplasma pneumonia by serology \& PCR in children with adenoid hypertrophy and rhinosinusitis: A case control study, 
Tehran, Iran. Iranian journal of microbiology 2013, 5(1):63.

33. Tuuminen T, Suni J, Kleemola M, Jacobs E: Improved sensitivity and specificity of enzyme immunoassays with P1-adhesin enriched antigen to detect acute Mycoplasma pneumoniae infection. Journal of microbiological methods 2001, 44(1):27-37.

34. Khoshbaten M, Rostami Nejad M, Farzady L, Sharifi N, Hashemi SH, Rostami K: Fertility disorder associated with celiac disease in males and females: fact or fiction? Journal of Obstetrics and Gynaecology Research 2011, 37(10):1308-1312.

35. Drasbek M, Nielsen PK, Persson K, Birkelund S, Christiansen G: Immune response to Mycoplasma pneumoniae $\mathrm{P} 1$ and $\mathrm{P} 116$ in patients with atypical pneumonia analyzed by ELISA. $B M C$ microbiology 2004, 4(1):7.

36. Shin JE, Cheon BR, Shim JW, Kim DS, Jung HL, Park MS, Shim JY: Increased risk of refractory Mycoplasma pneumoniae pneumonia in children with atopic sensitization and asthma. Korean journal of pediatrics 2014, 57(6):271.

37. Tanaka T, Oishi T, Miyata I, Wakabayashi S, Kono M, Ono S, Kato A, Fukuda Y, Saito A, Kondo E: Macrolide-resistant Mycoplasma pneumoniae infection, Japan, 2008-2015. Emerging infectious diseases 2017, 23(10):1703.

38. Meygret A, Le Roy C, Renaudin H, Bébéar C, Pereyre S: Tetracycline and fluoroquinolone resistance in clinical Ureaplasma spp. and Mycoplasma hominis isolates in France between 2010 and 2015. Journal of Antimicrobial Chemotherapy 2018, 73(10):2696-2703.

39. Lu A, Wang L, Zhang X, Zhang M: Combined treatment for child refractory Mycoplasma pneumoniae pneumonia with ciprofloxacin and glucocorticoid. Pediatric pulmonology 2011, 46(11):1093-1097.

40. Medjo B, Atanaskovic-Markovic M, Radic S, Nikolic D, Lukac M, Djukic S: Mycoplasma pneumoniae as a causative agent of community-acquired pneumonia in children: clinical features and laboratory diagnosis. Italian journal of pediatrics 2014, 40(1):104.

41. Rodrigues DM, Sousa AJ, Johnson-Henry KC, Sherman PM, Gareau MG: Probiotics are effective for the prevention and treatment of Citrobacter rodentium-induced colitis in mice. The Journal of infectious diseases 2012, 206(1):99-109.

42. Ataee RA, Golmohammadi R, Alishiri GH, Mirnejad R, Najafi A, ESMAEILI D, JONAIDI JN: Simultaneous detection of Mycoplasma pneumoniae, Mycoplasma hominis and Mycoplasma arthritidis in synovial fluid of patients with rheumatoid arthritis by multiplex PCR. 2015.

\section{Tables}

Table 1 Frequency distribution of cough and infection with M.pneumonia. 


\begin{tabular}{|lllll|}
\hline $\begin{array}{l}\text { Dry cough and } \\
\text { sputum }\end{array}$ & $\begin{array}{l}\text { Cough with } \\
\text { sputum }\end{array}$ & $\begin{array}{l}\text { Dry } \\
\text { cough }\end{array}$ & $\begin{array}{l}\text { No } \\
\text { cough }\end{array}$ & \\
\hline 0 & 3 & 4 & 0 & $\begin{array}{l}\text { Infected with } \\
\text { bacteria }\end{array}$ \\
\hline 17 & 41 & 26 & 9 & Not infected \\
\hline $0 / 214$ & $0 / 950$ & $0 / 104$ & $0 / 388$ & P-value \\
\hline
\end{tabular}

Table 2 MIC values of pneumococcal mycoplasma isolates

\begin{tabular}{|lll|}
\hline Antibiotic & MIC (micrograms per milliliter) & Sample Code \\
\hline Ciprofloxacin & $015 / 0$ & MD11 \\
\cline { 2 - 3 } & $003 / 0$ & MD22 \\
\hline $007 / 0$ & S4 \\
\hline $015 / 0$ & $\mathrm{CH} 19$ \\
\hline $007 / 0$ & $\mathrm{M} 93$ \\
\hline $506 / 0$ & $\mathrm{MD} 75$ \\
\hline $012 / 1$ & MD62 \\
\hline
\end{tabular}

Table 3 Compare antibody titers and PCR 


\begin{tabular}{|llcc|}
\hline \multicolumn{1}{|c}{ Sample code } & Pollution status & Antibody-unit header & Gender \\
\hline MD11 & Confirmation of Mycoplasma pneumonia & $43 / 6$ & $\mathrm{M}$ \\
\hline MD22 & Confirmation of Mycoplasma pneumonia & $41 / 9$ & $\mathrm{~F}$ \\
\hline S4 & Confirmation of Mycoplasma pneumonia & $64 / 8$ & $\mathrm{M}$ \\
\hline CH19 & Confirmation of Mycoplasma pneumonia & $36 / 2$ & $\mathrm{M}$ \\
\hline M93 & Confirmation of Mycoplasma pneumonia & $57 / 1$ & $\mathrm{~F}$ \\
\hline MD75 & Confirmation of Mycoplasma pneumonia & $39 / 9$ & $\mathrm{~F}$ \\
\hline MD62 & Confirmation of Mycoplasma pneumonia & $28 / 7$ & $\mathrm{~F}$ \\
\hline MD68 & Confirmation of mycoplasma & $40 / 6$ & $\mathrm{M}$ \\
\hline MD34 & Confirmation of mycoplasma & $25 / 4$ & $\mathrm{~F}$ \\
\hline M43 & Confirmation of mycoplasma & $32 / 3$ & $\mathrm{~F}$ \\
\hline B51 & Confirmation of mycoplasma & $25 / 4$ & $\mathrm{M}$ \\
\hline E12 & Confirmation of mycoplasma & $9 / 1$ & $\mathrm{~F}$ \\
\hline R4 & Confirmation of mycoplasma & $13 / 9$ & $\mathrm{M}$ \\
\hline B41 & Confirmation of mycoplasma & $14 / 66$ & \\
\hline
\end{tabular}

Table 4 Sequence of primers used in this study

\begin{tabular}{|llll|}
\hline Gene & Product size & Primer sequence & Reference \\
16S & $713 \mathrm{bp}$ & F: 5- ACTCCTACGGGAGGCAGCAGT - 3' & {$[41]$} \\
$r R N A$ & & R: 5- TGCACCATCTGTCACTCTGTTAACCTC - 3' & \\
\hline P1 & $450 \mathrm{bp}$ & F: 5- AAAGGAAGCTGACTCCGACA - 3' & {$[42]$} \\
& & R: 5- TGGCCTTGCGCTACTAAGTT -3' & \\
\hline
\end{tabular}

\section{Figures}




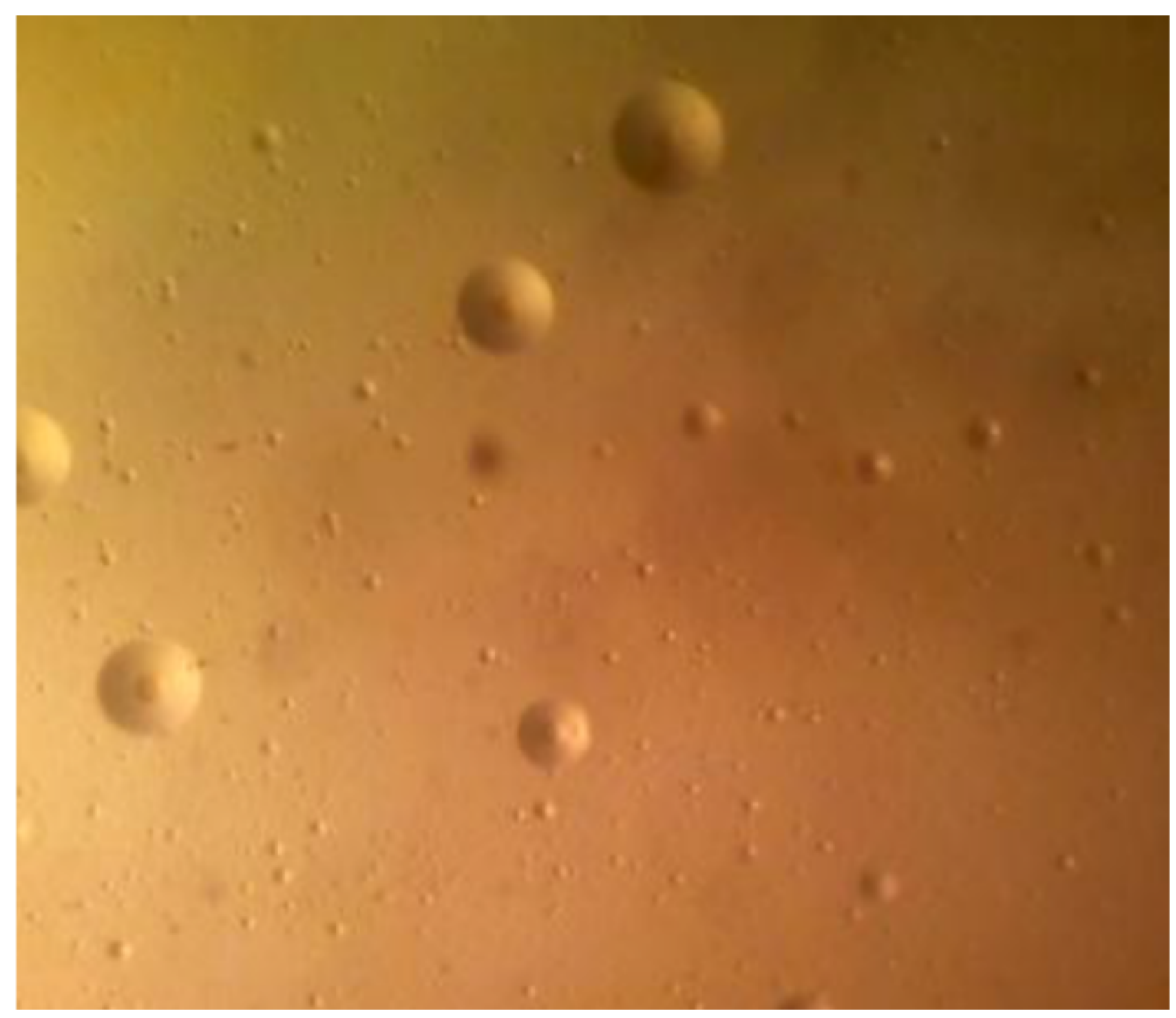

Figure 1

Half-egg structure on PPLO culture medium. 


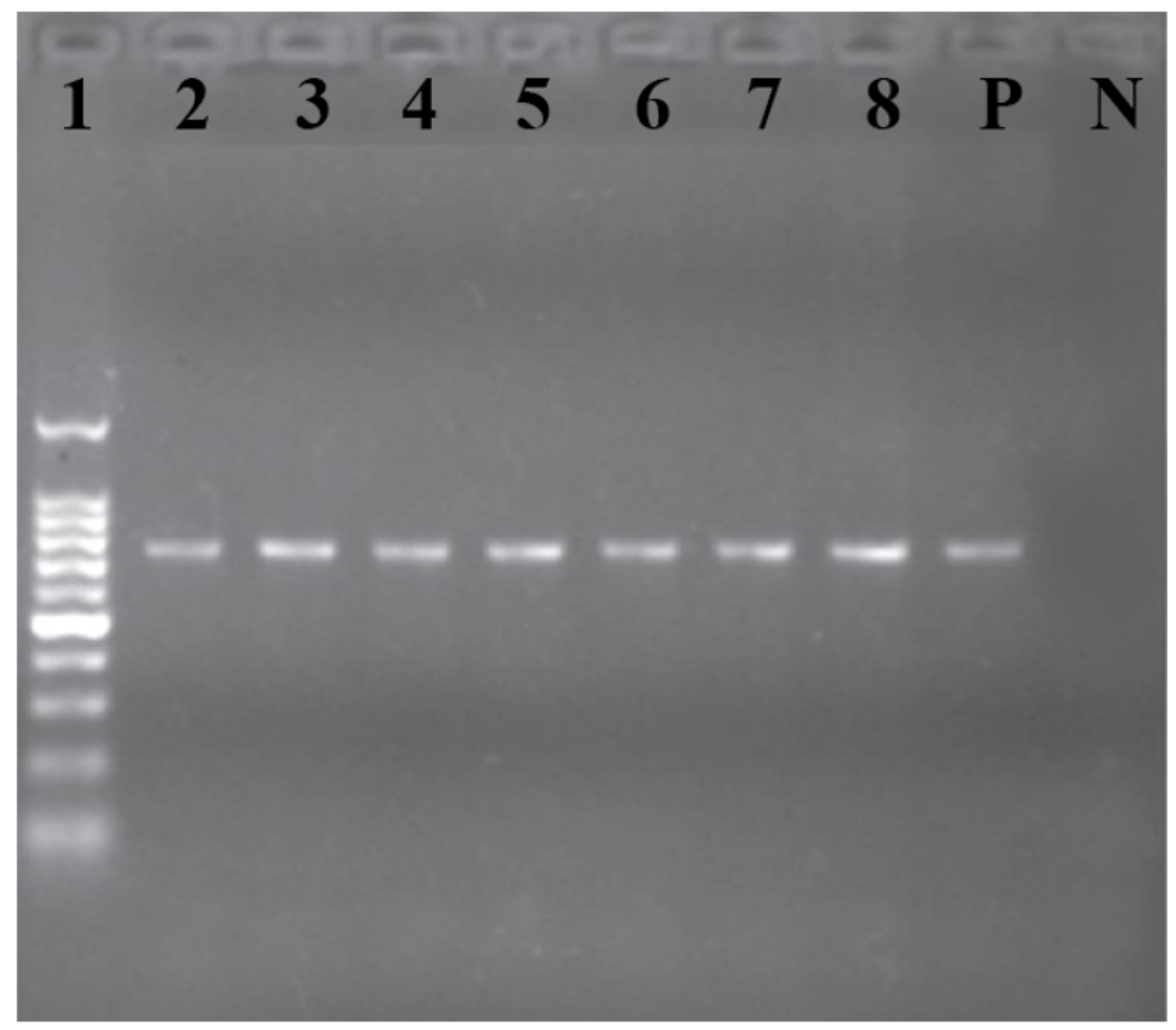

Figure 2

PCR product piece of the 16srRNA gene of the M.pneumoniae. P: Positive Control. N:NegativeControl. 1:Led Marker 


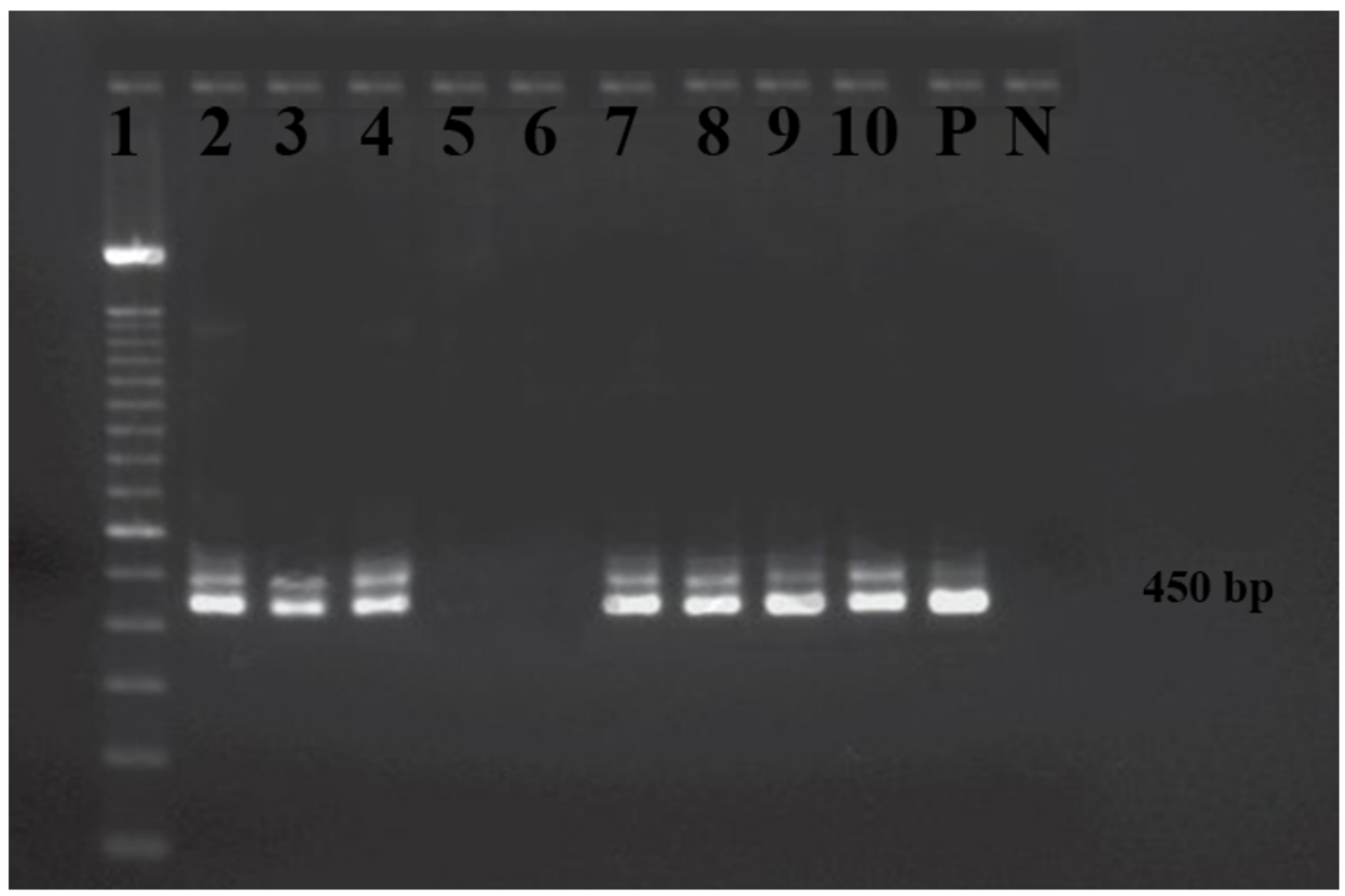

\section{Figure 3}

PCR product electrophoresis gel fragment of the P1 gene of M.pneumoniae. P: Positive Control. N: Negative Control. 1: Led Marker. 


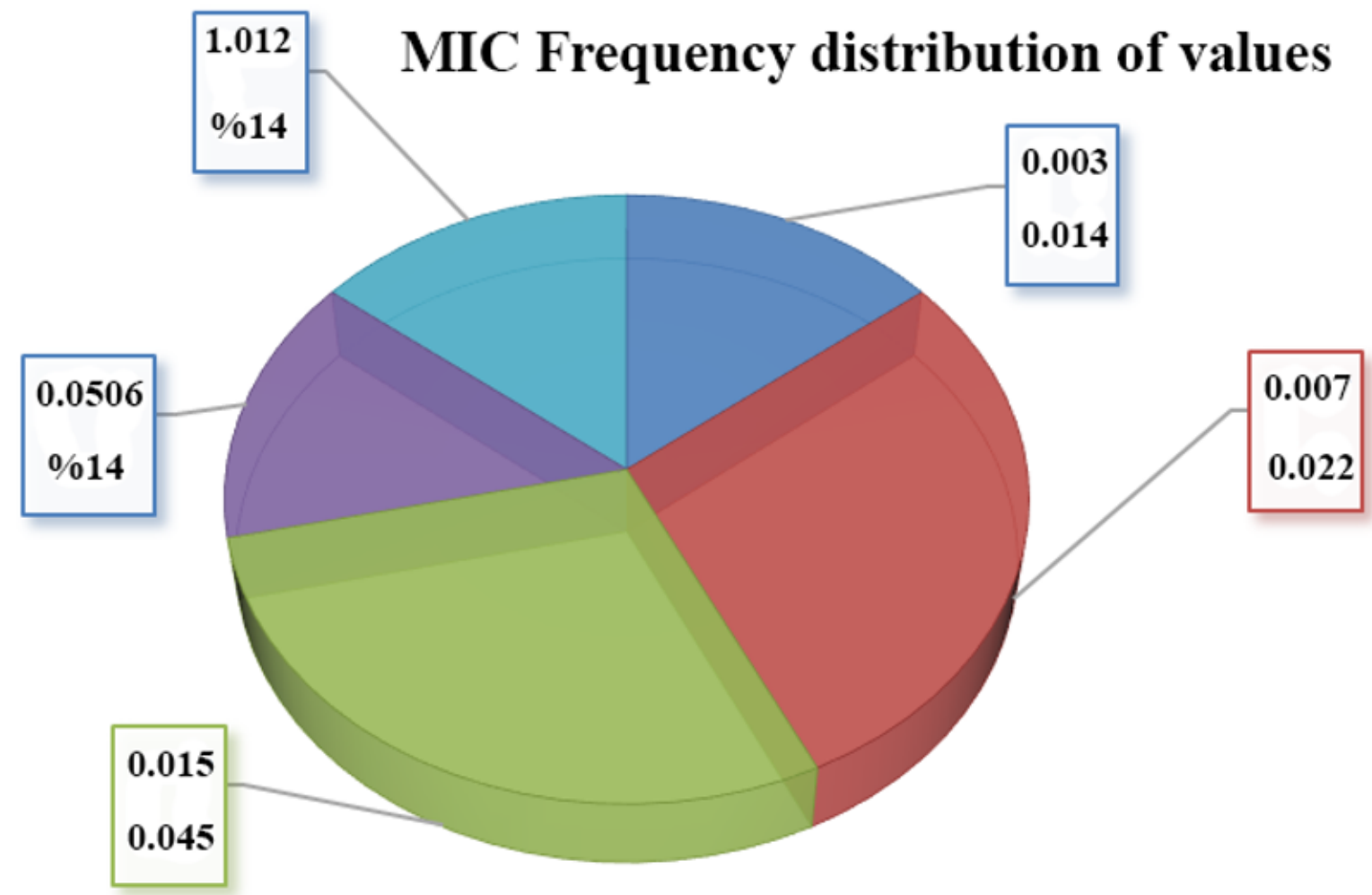

Figure 4

Abundant distribution of MIC in this study (values in micrograms per milliliter)

\section{Elisa Test}

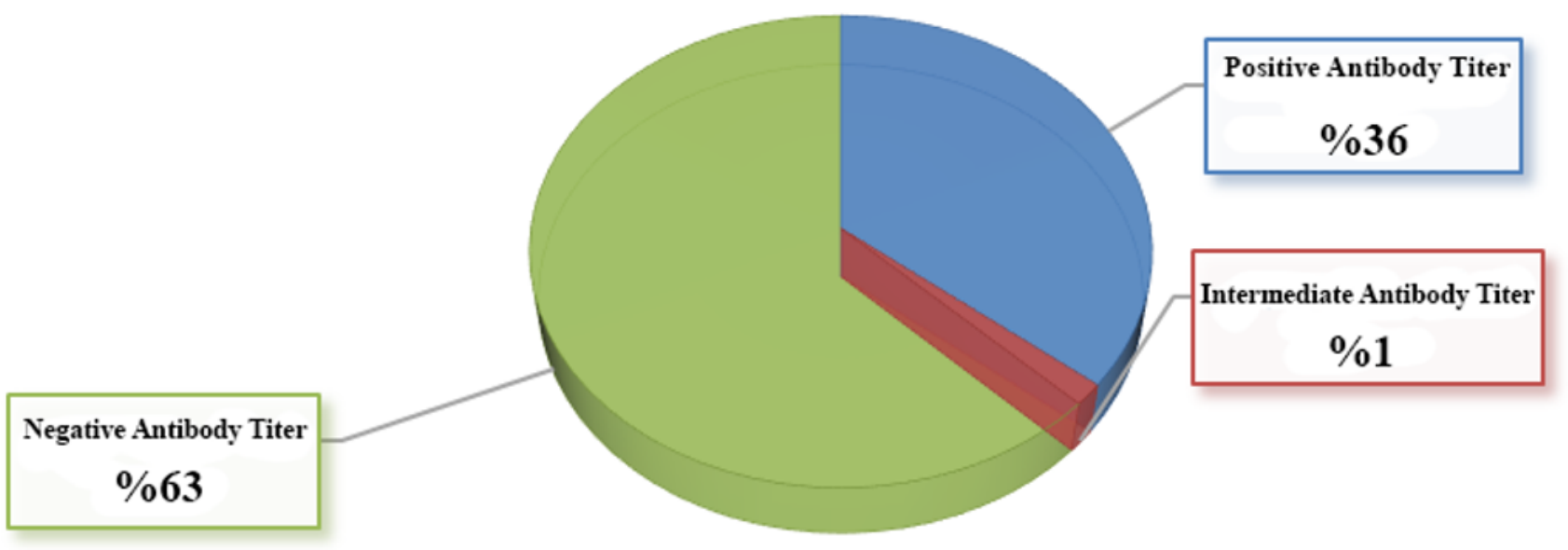

Figure 5

Specific IgG antibody to M.pneumoniae 


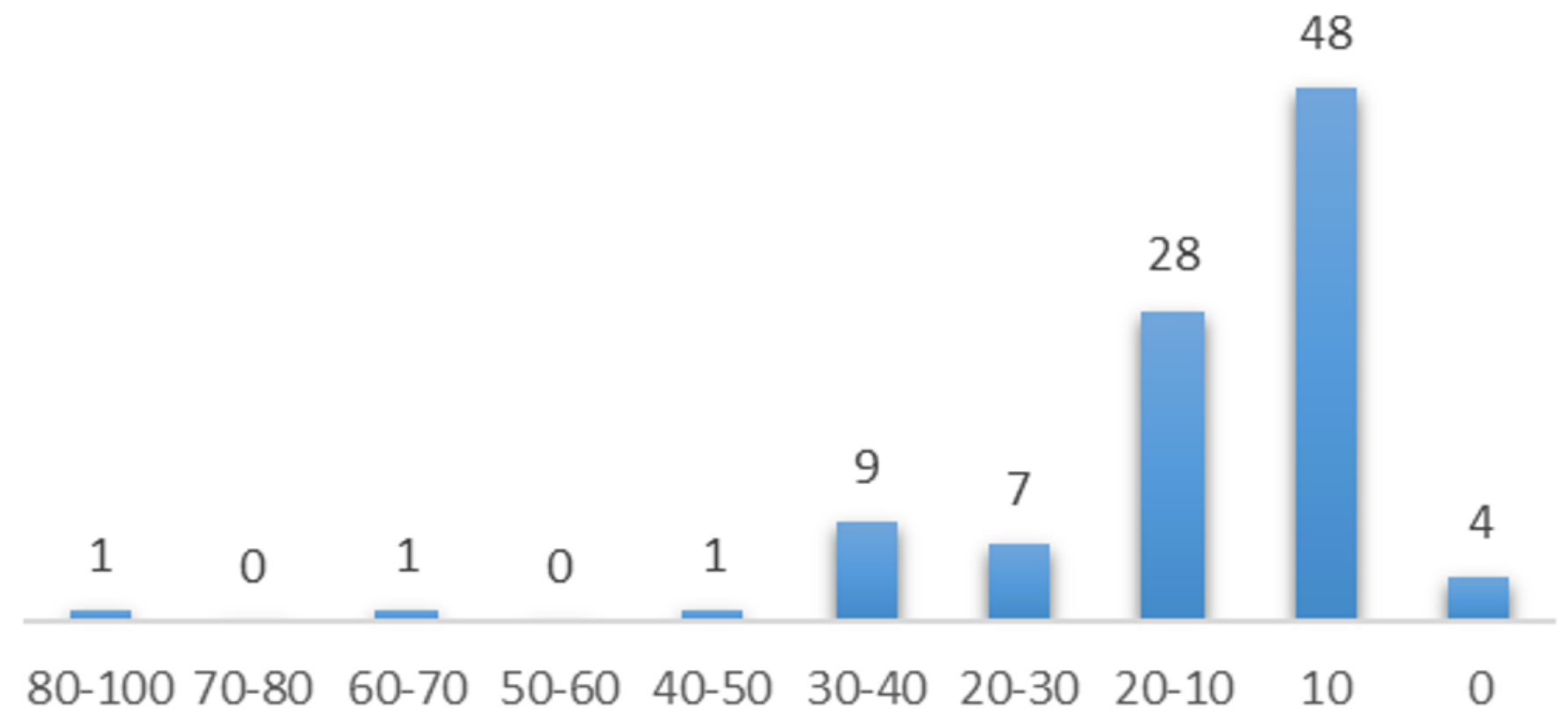

Figure 6

Frequency distribution of various IgG antibodies against M.pneumonia 